\section{The number of emergency department visits for psychiatric emergencies is strongly associated with mean temperature and humidity variations. Results of a nine year survey}

\section{Gianfranco Cervellin, ${ }^{1}$ Ivan Comelli, ${ }^{1}$ Giuseppe Lippi, ${ }^{2}$ Denis Comelli, ${ }^{3}$ Gianni Rastelli, ${ }^{4}$ Paolo Ossola, ${ }^{5}$ Carlo Marchesi ${ }^{5}$}

'Emergency Department, Parma University Hospital; ${ }^{2}$ Laboratory of Clinical Chemistry and Haematology, Parma University Hospital; ${ }^{3}$ National Institute of Nuclear Physics, University of Ferrara; ${ }^{4}$ Emergency Department, Hospital of Vaio, Fidenza; ${ }^{5}$ Psychiatric Clinic, University of Parma, Italy

\section{Abstract}

Several disorders, such as renal colics, stroke, atrial fibrillation and others, are epidemiologically associated with seasonality and microclimatic variations. Although evidence is still limited, an association between psychiatric emergencies and seasonality has also been previously described. In order to elucidate the possible association between weather and incidence of psychiatric emergencies in a country with temperate climate, we analyzed the influence of day by day climate changes on the number of visits for psychiatric emergencies in an urban emergency department (ED) of northern Italy. All ED visits for psychiatric emergencies were retrieved from the hospital database from 2002 to 2010. The total number of ED visits was 725,812 throughout the study period, 11,786 of which for emergency psychiatric problems. We found a strong seasonal distribution of emergency psychiatric visits, peaking in summer and at the beginning of spring. The linear regression analysis showed a strong positive association between number of daily emergency psychiatric visits and mean daily air temperature $(\mathrm{R}=0.82 ; \mathrm{P}<0.001)$, and an inverse association with mean daily air humidity $(\mathrm{R}=-0.52$; $\mathrm{P}<0.001)$. These findings suggest that psychiatric disorders follow a significant seasonal variation, so that it may be advisable to strengthen psychiatric emergency services during the hottest months.

\section{Introduction}

The existence of a relationship between meteorological variables, human behavior and diseases has been a matter of debate since ancient times, and has entrenched more in popular belief and in myths than in scientific knowledge. ${ }^{1}$ From the middle of the past century, however, this phenomenon has been investigated with more appropriate epidemiological and clinical tools, so that we have now reached a point where we can better analyze some popular beliefs under the light of science. Several studies, with different strength of evidence, have shown that an association may exist between meteorological variables and different human disorders such as stroke, ${ }^{2,3}$ renal colic, ${ }^{4,5}$ myocardial infarction, ${ }^{6}$ atrial fibrillation, ${ }^{7-10}$ asthma, ${ }^{11,12}$ and arthritic pain. ${ }^{13}$ Subjective experiences referred from patients, including variation in pain thresholds and mood swings associated with weather changes, seem to support the existence of a genuine relationship and pave the way to further research on this topic.

The seasonality in mental disorders has been recognized for long. A worsening of symptoms has been observed in winter and spring for unipolar depression, ${ }^{14,15}$ in fall for bipolar depression, ${ }^{16}$ in spring/summer for manic episodes, ${ }^{17-19}$ in August and December for panic disorder, ${ }^{20,21}$ and in winter for eating disorders. ${ }^{22-24}$ Moreover, a seasonal variation of suicide rates has been also observed, ${ }^{25-27}$ peaking in springtime. ${ }^{28,29}$

Since psychiatric patients, especially with anxiety and depressive disorders, are known to be high users of emergency medical services ${ }^{30-32}$ a relationship between weather conditions and number of visits to the emergency department (ED) should be expected. Nevertheless, only a limited number of studies has focused on the relationship between seasonality and ED visits for psychiatric emergencies, ${ }^{33-35}$ or has been specifically designed to explore the association with meteorological variables. ${ }^{36-40}$

Therefore, the aim of this study was to investigate the association between the rate of ED visits for psychiatric emergencies and variations of air temperature or humidity assessed on a daily basis.

\section{Materials and Methods}

All data about patients for whom a psychiatric visit was requested by the emergency physician of the ED of the University Hospital of Parma from 1 January 2002 to 31 December 2010 (3287 days) were retrieved from the database of our facility. Information about the pre-
Correspondence: Gianfranco Cervellin, Emergency Department, Parma University Hospital, Via Gramsci 14, 43126 Parma, Italy.

Tel. +39.0521.703800 - Fax: +39.0521 .703144$

E-mail: gcervellin@ao.pr.it

Key words: psychiatric emergencies, climate, temperature, humidity, emergency department.

Received for publication: 6 February 2014.

Revision received: 23 April 2014.

Accepted for publication: 23 April 2014.

This work is licensed under a Creative Commons Attribution 3.0 License (by-nc 3.0).

(c) Copyright G. Cervellin et al., 2014

Licensee PAGEPress, Italy

Emergency Care Journal 2014; 10:2271

doi:10.4081/ecj.2014.2271

cise onset of symptoms is lacking, but virtually every behavioral emergency is referred to the ED within a few hours in our area. It is not usual for patients to return to the ED within days or weeks for the same psychiatric emergency, because $41 \%$ of them have been admitted to a psychiatric ward, and every patient discharged from ED is typically referred to a psychiatric outpatient follow-up. However, a significant number of repeated visits for the same patient has been recorded (i.e., $58 \%$ of the visits are related to patients visited in the ED more than once during the observational period). With few and negligible exceptions, the vast majority of patients were residents in town or in the immediate neighborhood, within $20 \mathrm{~km}$ from the weather monitoring station. Urban and rural populations were represented in a nearly equal frequency, according to the distribution of population in our province. The University Hospital of Parma is a 1250 bed teaching general hospital, serving a population of about 340,000 inhabitants, and it is the only hospital in the area. Our hospital is also a level 2 Trauma Center, and a referral center for stroke and myocardial infarction. The population of our region is relatively stable, with the only exception of immigration, which causes a consistent increase of approximately $0.5 \%$ inhabitants per year, so that fluctuation in number of visits within the same year is unlikely to be attributable to variation in number of inhabitants. For all the 3287 observed days, the meteorological data referred to the province of Parma were obtained from the Environment and Climate Regional Agency of Emilia-Romagna Region. ${ }^{41}$ The site of measurement, located downtown, was at 10.330313 longitude; 44.808064 north latitude; $54 \mathrm{~m}$ asl. The climate at that site is considered as typical of the central-southern Pianura Padana area (the so-called Po river valley), and hence con- 
tinental with $777 \mathrm{~mm}$ precipitation per year, peaking in fall and spring. The peak of raining season is in October (averaging $110.2 \mathrm{~mm}$ per day), whereas July is typically the driest month (averaging $37.6 \mathrm{~mm}$ per day). The summer is hot and humid, with peak temperatures ranging from 30 to $35^{\circ} \mathrm{C}$, while winter is cold, with minimum temperatures seldom below $-20^{\circ} \mathrm{C}$. The mean estimated temperature throughout the study period was $13.5^{\circ} \mathrm{C}\left( \pm 8.6^{\circ} \mathrm{C}\right)$. The number of days with temperature comprised within one standard deviation was 1902 (i.e., $58 \%)$. The relative mean humidity in this area was $71 \%$ throughout the study period, with a maximum of $100 \%$ and a minimum of $28 \%$ in January and March, respectively (Table 1). ${ }^{41}$ The measurements of air temperature and humidity used in this study were performed on a 1-h basis, and the mean temperature and humidity of each single day was then calculated. The chronological data of all visits for psychiatric emergencies were associated with climate data by multiple univariate linear regression analyses, using the program Mathematica $7^{\circledR}$. We then developed a linear model with assumed independent normally distributed errors, providing a formatted analysis of variance table for the model (ANOVA). The $t$ statistics is the estimates divided by the standard errors. Each $P$ value is the two-sided $P$ value for the $t$ statistics and can be used to assess whether the parameter estimate is significantly different from zero. In particular, we calculated univariate linear regression analysis between the number of visits for psychiatric emergencies and the mean daily temperature $\left({ }^{\circ} \mathrm{C}\right)$ or the mean daily humidity (\%).

\section{Results}

Our local ED recorded 725,812 patient visits throughout the observational period, with an average of 221 patients per day. The total amount of visits increased from 80,538 in 2002 to 83,919 in 2010 , thus showing a positive incremental trend. A total of 11,786 emergency psychiatric visits were recorded during the same period (51\% males and 49\% females). The mean age of the entire population was $40 \pm 16$ years, and the distribution for age and gender is shown in Table 2. It is noteworthy that, in our facility, behavioral emergencies related to dementia are classified as geriatric emergencies, and thus are usually not referred to the psychiatrist. The small number of elderly patients mostly represent true elderly psychiatric patients. The rate of admission to a psychiatric ward, following the ED psychiatric visit, was $41 \%$. We found a strong seasonal distribution of emergency psychiatric visits, peaking in summer and at the beginning of spring (Figure 1). We also observed a strong positive association between number of daily emer-

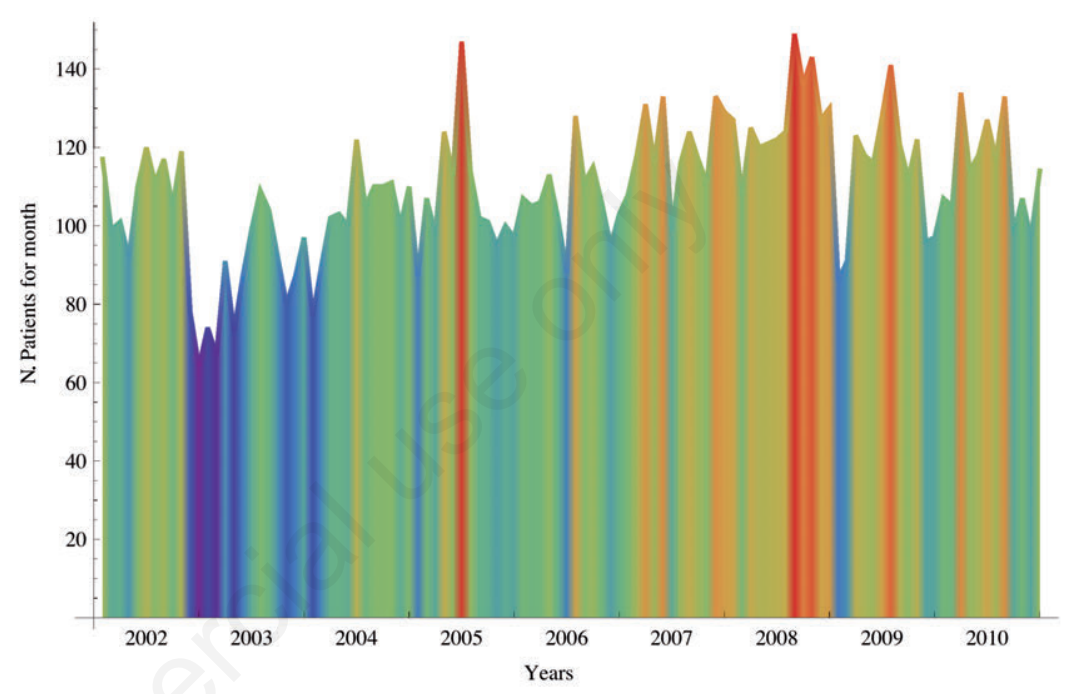

Figure 1. Trend of monthly number of emergency department visits for psychiatric emergencies during all the observation period.

Table 1. Average weather characteristics of the province of Parma stratified by month.

\begin{tabular}{|c|c|c|c|c|c|c|c|c|c|c|c|c|c|}
\hline & January & February & March & April & May & June & July & August & September & October & November & December & Annual \\
\hline $\begin{array}{l}\text { Average max. } \mathrm{T},{ }^{\circ} \mathrm{C} \\
\left({ }^{\circ} \mathrm{F}\right)\end{array}$ & $4(39)$ & $8(46)$ & $14(57)$ & $19(66)$ & $24(75)$ & $28(82)$ & $31(88)$ & $30(86)$ & $26(79)$ & $19(66)$ & $11(52)$ & $6(43)$ & $18(65)$ \\
\hline Average $\mathrm{T},{ }^{\circ} \mathrm{C}\left({ }^{\circ} \mathrm{F}\right)$ & $1(34)$ & $4(39)$ & $9(48)$ & $14(56)$ & $18(64)$ & $22(72)$ & $25(76)$ & $24(74)$ & $21(69)$ & $15(58)$ & $8(46)$ & $4(38)$ & $14(56)$ \\
\hline $\begin{array}{l}\text { Average min. } \mathrm{T},{ }^{\circ} \mathrm{C} \\
\left({ }^{\circ} \mathrm{F}\right)\end{array}$ & $-2(28)$ & $0(32)$ & $4(39)$ & $8(46)$ & $12(54)$ & $16(61)$ & $18(64)$ & $17(63)$ & $15(59)$ & $10(50)$ & $5(41)$ & $1(34)$ & $9(48)$ \\
\hline $\begin{array}{l}\text { Average } \\
\text { precipitation, } \\
\text { mm (in) }\end{array}$ & $40(2)$ & $53(2)$ & $76(3)$ & $93(4)$ & $65(3)$ & $64(3)$ & $47(2)$ & $47(2)$ & $70(3)$ & $96(4)$ & $114(4)$ & $78(3)$ & $843(33)$ \\
\hline $\begin{array}{l}\text { Wet days, } \mathrm{n} \\
\text { (probability of } \\
\text { rain on a day, \%) }\end{array}$ & $6(19)$ & $7(25)$ & $8(26)$ & $9(30)$ & $7(23)$ & $7(23)$ & $5(16)$ & $5(16)$ & $5(17)$ & $8(26)$ & $10(33)$ & $8(26)$ & $85(23)$ \\
\hline $\begin{array}{l}\text { Average sunlight, } \\
\text { h/day }\end{array}$ & $02: 29$ & 04:40 & 04:30 & 06:32 & 08:29 & $10: 10$ & $10: 54$ & 09:32 & 08:14 & 05:11 & 01:50 & 01:38 & 06:11 \\
\hline $\begin{array}{l}\text { Average daylight, } \\
\text { h \& min/day }\end{array}$ & 09:12 & $10: 20$ & $11: 50$ & 13:26 & 14:48 & $15: 30$ & $15: 11$ & 14:00 & $12: 27$ & $10: 52$ & 09:30 & 08:50 & 12:00 \\
\hline $\begin{array}{l}\text { Sunny daylight } \\
\text { hours, } \%\end{array}$ & 28 & 46 & 39 & 49 & 58 & 66 & 73 & 69 & 67 & 49 & 20 & 19 & 52 \\
\hline $\begin{array}{l}\text { Cloudy daylight } \\
\text { hours, } \%\end{array}$ & 72 & 54 & 61 & 51 & 42 & 34 & 27 & 31 & 33 & 51 & 80 & 81 & 48 \\
\hline
\end{tabular}


gency psychiatric visits and mean daily air temperature $(\mathrm{T})(\mathrm{R}=0.82 ; \mathrm{P}<0.001)$ (Figure 2), which could be described by the following equation:

Number of emergency psychiatric visits a day $=3.2526-0.02452 \mathrm{~T} /{ }^{\circ} \mathrm{C}$

Mean temperature (T) was hence strongly associated with the number of emergency psychiatric visits. In particular, the number of emergency psychiatric visits was 3.25 per day for winter days with a $\mathrm{T}$ near $0^{\circ} \mathrm{C}$, while the number of emergency psychiatric visits was 4.0 per day in hot summer days with $\mathrm{T}$ near $30^{\circ} \mathrm{C}$, with a relative increase of $22.6 \%$.

We also found an inverse association between number of daily emergency psychiatric visits and mean daily air humidity $(\mathrm{R}=-0.52$; $\mathrm{P}<0.001$ ) (Figure 3), which was described by the following equation:

Number of emergency psychiatric visits a day $=4.277-0.00963 \mathrm{H} / \%$

Mean humidity $(\mathrm{H})$ was inversely associated with the number of emergency psychiatric visits. The number of emergency psychiatric visits was 4.0 per day in dry summer days with $\mathrm{H}$ close to $28 \%$, whereas, the number of emergency psychiatric visits was 3.31 per day in winter days with $\mathrm{H}$ close to $99 \%$, with a relative variation of $-17.3 \%$.

As mentioned above, a significant number of repeated visits was recorded. Specifically, $42 \%$ of the visits were performed for patients visited only once in 9 years, whereas $58 \%$ of the visits were related to patients visited in the ED more than once during the same period. In particular, 4299 visits were performed for 1470 patients who were visited less than once per year, whereas 782 visits were performed for only 9 patients, visited more than 50 times during the observational period (in one remarkable case, reaching 175 times). Obviously, the latter group represents the typical frequentflyer patients, i.e., alcoholic, addicted and homeless subjects.

\section{Discussion}

In this study, which is supposed to be the largest ever performed to investigate the association between short term variation of climate and number of ED visits for psychiatric emergencies, we explored the relationship between temperature and humidity recorded on a daily basis and the rate of ED visits for psychiatric emergencies.

According to the results of this retrospective investigation, two main findings emerged. First, we were able to confirm the existence of a strong positive association between air temperature and number of ED visits for psychiatric emergencies in a region with continental and temperate climate. Second, we found a negative association between air humidity and number of psychiatric emergencies.

These findings confirm the results of previous studies, which found a positive association between ED psychiatric visits and temperature, ${ }^{33,36-40}$ while only partially overlap with studies that observed an impact of heat waves (high temperature and humidity) on ED psychiatric visits. ${ }^{37-39} \mathrm{~A}$ possible explanation of this discrepancy could lie in the different study design. Indeed, we considered a nine year period com- pared with three ${ }^{37}$ or five months per year, ${ }^{39}$ in a temperate continental climate setting different from the continental/sub-arctic one. ${ }^{39}$

Researchers have formulated several hypotheses about the influence of the weather on human behaviors, although a small number of defined syndromes have been proposed in the literature so far. The serotonin irritation syndrome, for example, has been described as an anxiety state occurring in the presence of elevated levels of atmospheric or ambient cations, and is associated with elevated central and peripheral serotonin levels. It is clinically characterized by anxiety, insomnia, migraines, vomiting, breathing difficulty and rheumatoid

Table 2. Whole population subdivided by age groups and gender.

\begin{tabular}{lccc} 
Age groups (years) & Male $(\mathrm{n})$ & Female $(\mathrm{n})$ & Total (n) \\
$0-10$ & 0 & 1 & 1 \\
$11-20$ & 352 & 192 & 544 \\
\hline $21-30$ & 1036 & 1020 & 2056 \\
$31-40$ & 1449 & 1838 & 3287 \\
\hline $41-50$ & 1382 & 1470 & 2852 \\
$51-60$ & 874 & 530 & 1404 \\
\hline $61-70$ & 475 & 280 & 755 \\
$71-80$ & 310 & 205 & 515 \\
\hline $81-90$ & 213 & 128 & 341 \\
$91-100$ & 15 & 16 & 31 \\
\hline Total & 6106 & 5680 & 11,786 \\
\hline
\end{tabular}

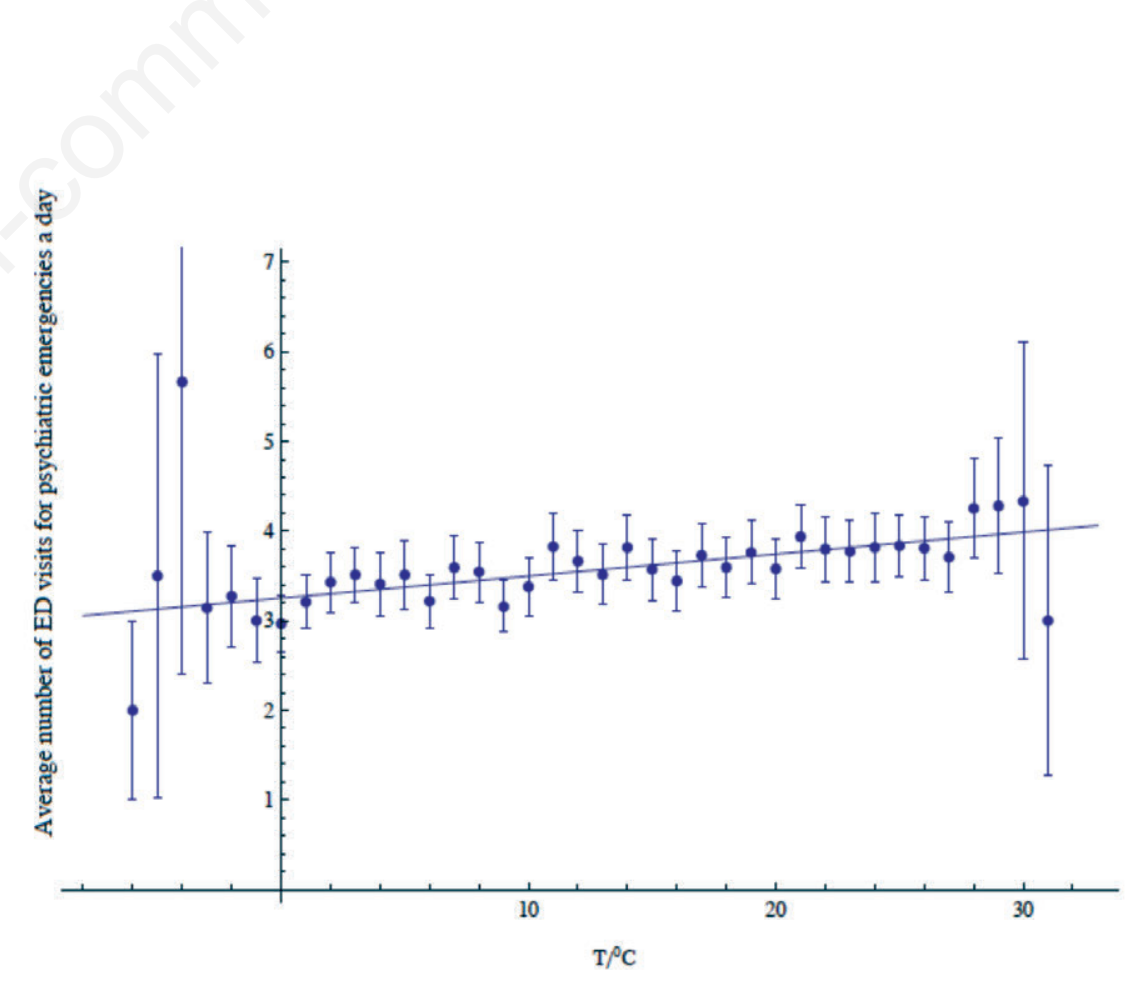

Figure 2. Correlation between emergency department visits for psychiatric emergencies and mean daily temperature. 
pain. ${ }^{42,43}$ We can thus suppose that these symptoms, in an already vulnerable psychiatric patient, could trigger a psychiatric emergency. Although mainly supported by animal studies, an exhaustion syndrome, associated with warm winds and heat waves, has been described in association with a deficiency of catecholamines, with symptoms such as hypotension, fatigue, apathy, lack of concentration and episodes of hypoglycaemia. ${ }^{44}$ Unfortunately, no studies have been performed in humans so far, which could hence confirm the aforementioned hypothesis.

The correlation between low humidity and psychological distress has been widely studied indoor. The sick building syndrome ${ }^{45}$ postulates that low humidity in association with high temperature or other factors (i.e., air ventilation, dust) may produce an effect on workers' health. In particular, an increase of humidity was found to be associated with decreasing symptoms. ${ }^{46}$ Interestingly, another study ${ }^{33}$ described that warm and dry winds, associated with low humidity and high positive ions, were positively correlated with the levels of agitation in ED patients. Therefore, we can hypothesize that high temperature and low humidity have a double adding effect on human psychology.

Intolerance to heat waves has also been observed in psychiatric patients. This could be attributed to both abnormal thermoregulation $^{47,48}$ and behavioral habits. ${ }^{39}$ Psychotic patients, in particular, lack in autonomy and tend not to use medical services ${ }^{49}$ despite the greater burden of medical comorbidity with a lower life expectancy than the general population. ${ }^{50,51}$ Other factors may influence heat vulnerability among persons with mental illness, such as insufficient hydration, inappropriate clothing, and persons with paranoid, avoidant, schizoid, or agoraphobic symptoms may be reluctant to leave home. Moreover, a decrease in the availability of significant caregivers (family members) or medical and mental health services (general practitioners, psychiatrists) has been observed in summer, probably because of the holidays. Accordingly, worse consequences of substance assumption have been described in patients with substance use disorders with higher temperatures,${ }^{52}$ along with an increase of admissions for dementia, i.e., for dehydration and electrolytic imbalance..$^{53}$

It is also noteworthy that seasonality of psychiatric disorders itself could have influenced our results, which may be reflected by the peak in August of panic attacks ${ }^{54}$ associated with the increase of manic/hypomanic episodes..$^{55,56}$

In our ED we have observed a slight decrease of total visits during summer months in the last fifteen years, with July and August exhibiting a 5 to $8 \%$ lower prevalence than March or November. Therefore, we can not explain our findings in terms of correlation with increase of total ED visits.

As reported in the Methods section above, the population of our region is relatively stable, with the only exception of immigration, which causes a consistent increase of approximately $0.5 \%$ inhabitants per year. As earlier observed in a five year survey ${ }^{57}$ the immigrants account for $15.4 \%$ of the total Parma's ED visits, despite representing $13.5 \%$ of the whole population. This percentage seems to be stable, so that fluctuation in the number of visits within the same year is unlikely to be attributable to variation in the number of inhabitants.

This large investigation has some limitations. The time of the visit is related to the onset of symptoms, and obviously not of the disease. However, the significance of our findings relies in the potential effect of climate in decompensating a clinical problem, rather than in the more complex and still largely unknown field of ethiology of psychiatric disorders. This also holds true, for example, in the correlations found between renal colics and climate variations, since the pathogenesis of renal stones is a complex, time-consuming and multifaceted process, but the abrupt onset of the colic just entails a short period, in a specific clinical and environmental condition. ${ }^{4,5}$ Due to lack of data, we could not analyze the possible correlations with other climatic variable, such as winds, ${ }^{58}$ day-light ${ }^{59}$ and time spent outside. ${ }^{60}$ We here describe a heterogeneous sample of patients visited for psychiatric emergencies, and it remains unclear whether different diagnostic subgroups may display similar correlations. We have just started a prospective study, where the same climatic correlations will be investigated in patients subdivided in different psychopathological categories. The number of repeated visits for the same patients recorded throughout the entire period should also be considered as a predictable finding, since it is well recognized that psychiatric patients, alongside with alcoholic ones, are likely to be frequent visitors. ${ }^{61}$

\section{Conclusions}

Psychiatric emergencies clearly have more complex causes rather than just meteorological factors. In some cases, weather might be a triggering factor, and the findings of the present study suggest that it may be advisable to strengthen psychiatric emergency services during hot months. Since most of the patients are unaware of the risks from temperature/humidity exposure, suitable psycho-education counseling should be combined with outpatient care programs. Future research should also focus on the impact of other environmental variables and evaluate risk assessment and precautionary perspectives on specific disorders.

\section{References}

1. Bulbena A, Pailhez G, Aceña R, et al. Panic anxiety, under the weather? Int $\mathrm{J}$ Biometeorol 2005;49:238-43.
Figure 3. Correlation between emergency department visits for psychiatric emergencies and mean daily humidity. 
2. Wang H, Sekine M, Chen X, Kagamimori S. A study of weekly and seasonal variation of stroke onset. Int $\mathbf{J}$ Biometeorol 2002;47:13-20.

3. Magalhães R, Silva MC, Correia M, Bailey T. Are stroke occurrence and outcome related to weather parameters? Results from a population-based study in northern Portugal. Cerebrovasc Dis 2011;32:542-51.

4. Cervellin G, Comelli I, Comelli D, et al. Regional short-term climate variations influence on the number of visits for renal colic in a large urban Emergency Department: results of a 7-year survey. Intern Emerg Med 2011;6:141-7.

5. Cervellin G, Comelli I, Comelli D, et al. Mean temperature and humidity variations, along with patient age, predict the number of visits for renal colic in a large urban Emergency Department: results of a 9-year survey. J Epidemiol Glob Health 2012;2:31-8.

6. Bhaskaran K, Hajat S, Haines A, et al. Short term effects of temperature on risk of myocardial infarction in England and Wales: times series regression analysis of the Myocardial Ischaemia National Audit Project (MINAP) Registry. Brit Med J 2010;341-7.

7. Frost L, Johnsen SP, Pedersen L, et al. Seasonal variation on hospital discharge diagnosis of atrial fibrillation: a population based study. Epidemiology 2002;13:211-5.

8. Watanabe E, Kuno Y, Takasuga H, et al. Seasonal variation in paroxysmal atrial fibrillation documented by 24-hour Holter electrocardiogram. Heart Rhythm 2007;4:27-31.

9. Cervellin G, Comelli I, Lippi G. Lack of correlation between air pollution and acuteonset atrial fibrillation. Can J Cardiol 2013;29:1743.e9.

10. Comelli I, Ferro J, Lippi G, et al. Incidence of acute-onset atrial fibrillation correlates with air temperature. Results of a nineyears survey. J Epidemiol Glob Health 2014 (in press).

11. Beard JD, Beck C, Graham R, et al. Winter temperature inversions and emergency department visits for asthma in Salt Lake County, Utah, 2003-2008. Environ Health Persp 2012;120:1385-90.

12. Wasilevich EA, Rabito F, Lefante J, Johnson E. Short-term outdoor temperature change and emergency department visits for asthma among children: a casecrossover study. Am J Epidemiol 2012;176:123-30.

13. Redelmeier DA, Tversky A. On the belief that arthritis pain is related to the weather. P Natl Acad Sci USA 1996;93:2895-6.

14. Blacker CV, Thomas JM, Thompson C. Seasonality prevalence and incidence of depressive disorder in a general practice sample: identifying differences in timing by caseness. J Affect Disorders 1997;43:41-52.
15. Vigod SN, Levitt AJ. Seasonal severity of depressive symptoms as a predictor of health service use in a community-based sample. J Psychiatr Res 2011;45:612-8.

16. Sato T, Bottlender R, Sievers M, Möller HJ. Distinct seasonality of depressive episodes differentiates unipolar depressive patients with and without depressive mixed states. J Affect Disorders 2006;90:1-5.

17. Volpe FM, Del Porto JA. Seasonality of admissions for mania in a psychiatric hospital of Belo Horizonte, Brazil. J Affect Disorders 2006;94:243-8.

18. Volpe FM, Tavares A, Del Porto JA. Seasonality of three dimensions of mania: psychosis, aggression and suicidality. J Affect Disorders 2008;108:95-100.

19. Yang AC, Yang CH, Hong CJ, et al. Effects of age, sex, index admission, and predominant polarity on the seasonality of acute admissions for bipolar disorder: a populationbased study. Chronobiol Int 2013;30:478-85.

20. Marriott PF, Greenwood KM, Armstrong SM. Seasonality in panic disorder. J Affect Disorders 1994;31:75-80.

21. Ohtani $\mathrm{T}$, Kaiya $\mathrm{H}$, Utsumi $\mathrm{T}$, et al. Sensitivity to seasonal changes in panic disorder patients. Psychiatry Clin Neurosci 2006;60:379-83.

22. Fornari VM, Braun DL, Sunday SR, et al. Seasonal patterns in eating disorder subgroups. Compr Psychiat 1994;35:450-6.

23. Lam RW, Goldner EM, Grewal A. Seasonality of symptoms in anorexia and bulimia nervosa. Int J Eat Disorder 1996;19:35-44.

24. Ghadirian AM, Marini N, Jabalpurwala S, Steiger H. Seasonal mood patterns in eating disorders. Gen Hosp Psychiat 1999;21:354-9.

25. San Gil J, Gonzàlez de Rivera JL, Gonzàlez Gonzàlez J. [Tiempo clima y conductas auto y heteroagresivas]. In: DelgadoBueno S, ed. [Psiquiatrìa legal y forense]. [Book in Spanish]. Madrid, Spain: Colex; 1994. pp 178-84.

26. Christodoulou C, Douzenis A, Papadopoulos FC, et al. Suicide and seasonality. Acta Psychiat Scand 2012;125:127-46.

27. Woo JM, Okusaga 0, Postolache TT. Seasonality of suicidal behavior. Int $\mathrm{J}$ Environ Res 2012;9:531-47.

28. Maes M. Seasonality in violent suicide but not in nonviolent suicide or homicide. Am J Psychiat 1993;150:1380-5.

29. Ajdacic-Gross V, Wang J, Bopp M, et al. Are seasonalities in suicide dependent on suicide methods? A reappraisal. Soc Sci Med 2003;57:1173-81.

30. Marchesi C, Brusamonti E, Giannini A, et al. The use of an emergency ward by patients with depressive or anxiety disorders: a one year follow-up study. Int $\mathrm{J}$ Psychiat Med 2001;31:265-75.

31. Marchesi C, Brusamonti E, Borghi C, et al. Anxiety and depressive disorders in an emergency department ward of a general hospital: a control study. Emerg Med J 2004;21:175-9.

32. Schmoll S, Boyer L, Henry JM, Belzeaux R. Frequent visitors to psychiatric emergency service: demographical and clinical analysis. Encephale 2013 (in press).

33. San Gil J, Gonzàlez de Rivera JL, Gonzàlez J. [Meteorotropismo y estacionalidad de las urgencias psiquitricas en la isla de Tenerife]. [Article in Spanish]. Psiquis 1988;10:349-59.

34. Díaz RJ, Hidalgo I, Martín T, et al. Seasonality and psychiatric emergencies. Actas Luso-Esp Neuro 1996;24:253-9.

35. Singh GP, Chavan BS, Arun P, Sidana A. Seasonal pattern of psychiatry service utilization in a tertiary care hospital. Indian J Psychol 2007;49:91-5.

36. Santiago PN, McLay RN, Hammer PS. Meteorologic factors in emergency evaluation, admission, and discharge. Psychiatr Serv 2005;56:1625-9.

37. Bulbena A, Sperry L, Garcia Rivera C, et al. Impact of the summer 2003 heat wave on the activity of two psychiatric emergency departments. Actas Esp Psiquiatr 2009; 37:158-65.

38. García FM, Boada SS, Collsamata AX, et al. Meteorological factors and psychiatric emergencies. Actas Esp Psiquiatr 2009;37: 34-41.

39. Vida S, Durocher M, Ouarda TB, Gosselin P. Relationship between ambient temperature and humidity and visits to mental health emergency departments in Québec. Psychiatr Serv 2012;63:1150-3.

40. Wang X, Lavigne E, Ouellette-Kuntz H, Chen BE. Acute impacts of extreme temperature exposure on emergency room admissions related to mental and behavior disorders in Toronto, Canada. J Affect Disorders 2014;155:154-61.

41. ARPA. Dexter system. Agenzia Regionale Prevenzione e Ambiente - Environment and Climate Regional Agency ed. Available from: http://www.arpa.emr.it/sim/?osservazioni_e_dati/dexter

42. Giannini AJ. Serotonin irritation syndrome: a hypothesis. Int J Psychiat Med 1979;9:199-204.

43. Giannini AJ, Castellani S, Dvoredsky AE. Anxiety states: relationship to atmospheric cations and serotonin. J Clin Psychiat 1983;44:262-4.

44. Sulman FG. Effect of ambient heat stress on body development of rats and effect of drugs on heat stress survival. Israel J Med Sci 1976;12:1134-5.

45. Redlich CA, Sparer J, Cullen MR. Sick-building syndrome. Lancet 1997;349:1013-6.

46. Reinikainen LM, Jaakkola JJ, Seppänen 0 . The effect of air humidification on symptoms and environmental com- 
plaints in office workers. A six period cross-over trial. Arch Environ Health 1992;47:8-15.

47. Shiloh R, Weizman A, Epstein Y, et al. Abnormal thermoregulation in drug-free male schizophrenia patients. Eur Neuropsychopharm 2001;11:285-8.

48. Bouchama A, Dehbi M, Mohamed G, et al. Prognostic factors in heat wave related deaths: a meta-analysis. Arch Intern Med 2007;167:2170-6.

49. Cahoon EK, McGinty EE, Ford DE, Daumit GL. Schizophrenia and potentially preventable hospitalizations in the United States: a retrospective cross-sectional study. BMC Psychiatry 2013;13:37.

50. Harris EC, Barraclough B. Excess mortality of mental disorder. Brit J Psychiat 1998;173:11-53.

51. Lawrence D, Hancock KJ, Kisely S. The gap in life expectancy from preventable physical illness in psychiatric patients in Western Australia: retrospective analysis of population based registers. Brit Med J 2013;346:2539.

52. Page LA, Hajat S, Kovats RS, Howard LM. Temperature-related deaths in people with psychosis, dementia and substance misuse. Brit J Psychiat 2012;200:485-90.

53. Salib E, Sharp N. Does the weather influence dementia admissions? Int J Geriatr Psych 1999;14:925-35.

54. Buccelletti F, Ojetti V, Merra G, et al. Recurrent use of the Emergency Department in patients with anxiety disorder. Eur Rev Med Pharmaco 2013;17 (Suppl.1):100-6.

55. Carney PA, Fitzgerald CT, Monaghan CE. Influence of climate on the prevalence of mania. Brit J Psychiat 1988;152:820-3.

56. Christensen EM, Larsen JK, Gjerris A, et al. Climatic factors and bipolar affective disorder. Nord J Psychiat 2008;62:55-8.

57. Zinelli M, Musetti V, Comelli I, et al. Emergency department utilization rates and modalities among immigrant popula- tion. A 5-year survey in a large Italian urban emergency department. Emerg Care J 2014;10:1896.

58. Bos EH, Hoenders R, de Jonge P. Wind direction and mental health: a time-series analysis of weather influences in a patient with anxiety disorder. BMJ Case Rep 2012;2012:bcr2012006300.

59. Oren DA, Koziorowski M, Desan PH. SAD and the not-so-single photoreceptors. Am J Psychiat 2013;170:1403-12.

60. Keller MC, Fredrickson BL, Ybarra 0, et al. A warm heart and a clear head. The contingent effects of weather on mood and cognition. Psychol Sci 2005;16:724-31.

61. Minassian A, Vilke GM, Wilson MP. Frequent emergency department visits are more prevalent in psychiatric, alcohol abuse, and dual diagnosis conditions than in chronic viral illnesses such as hepatitis and human immunodeficiency virus. J Emerg Med 2013;45:520-5. 